\title{
A Simple and Sensitive RP-UPLC Method for the Simultaneous Determination of N- Hydroxybenzotriazole, Cinchonidine and 1,3- Dicyclohexyl Urea Contents in Fosinopril Sodium Drug Substance
}

\author{
M. NARENDRA KUMAR ${ }^{1 *}$, V. KRISHNA REDDY ${ }^{2 * *}$, HEMANT KUMAR SHARMA $^{1}$, \\ T. KALEEMULLAH ${ }^{1}$, T. CHANDRA SEKHAR REDDY ${ }^{1}$, G. THIRUPATHI REDDY ${ }^{1}$, N. \\ SREENIVAS $^{1}$, AND GOUTAM SEN ${ }^{1}$ \\ ${ }^{1}$ Aurobindo Pharma Limited Research Centre, 313, Bachupally, \\ Hyderabad-500 090, Andhra Pradesh, India \\ ${ }^{2}$ Department of Chemistry, Sri Krishnadevaraya University, \\ Anantapur-515 003, Andhra Pradesh, India \\ narendra_masani@yahoo.ie \\ krvanka@gmail.com
}

Received 28 October 2011; Accepted 30 December 2011

\begin{abstract}
A simple and sensitive reverse phase ultra performance liquid chromatography (RP-UPLC) method has been developed, optimized and validated for the simultaneous determination of N-Hydroxybenzotriazole $(\mathrm{HOBt})$, Cinchonidine and 1,3-Dicyclohexyl urea (DCU) contents at low levels in fosinopril sodium drug substance. Efficient chromatographic separation was achieved on Acquity UPLC HSS $\mathrm{C}_{18}$ column, $100 \mathrm{~mm}$ long with $2.1 \mathrm{~mm}$ i.d., $1.8 \mu \mathrm{m}$ particle diameter, thermo stated at $30^{\circ} \mathrm{C}$. Gradient elution involving binary mixture of potassium dihydrogen orthophosphate $(0.01 \mathrm{M}, \mathrm{pH}: 3.0 \pm 0.05$ with ortho-phosphoric acid) and acetonitrile at a flow rate of $0.10 \mathrm{~mL} \mathrm{~min}^{-1}$ has been used. The analytes were monitored by photodiode array (PDA) detector set at $205 \mathrm{~nm}$. The drug substance was subjected to stress conditions of hydrolysis, oxidation, photolysis, thermal and humidity degradation. The method was validated for specificity, sensitivity, linearity, precision, accuracy and solution stability. The limit of detection (LOD) and limit of quantification (LOQ) for HOBt, Cinchonidine and DCU were in the range of $0.85-3.52 \mathrm{ppm}$ and 2.57-10.67 ppm, respectively. The average recoveries for $\mathrm{HOBt}$, Cinchonidine and DCU are in the range of $98.1 \%$ to $102.6 \%$. The method can be used for the routine quality control analysis of fosinopril sodium drug substance.
\end{abstract}

Keywords: N-Hydroxybenzotriazole; Cinchonidine; 1,3-Dicyclohexyl urea; Fosinopril sodium; Validation. 


\section{Introduction}

Chemically Fosinopril sodium $\quad\left[1\left[S^{*}\left(R^{*}\right)\right], 2 \alpha, 4 \beta\right]-4-C y c l o h e x y l-1-[[[2-m e t h y l-1-(1-$ oxopropoxy)propoxy] (4-phenylbutyl)phosphinyl]acetyl]-L-proline, monosodium salt, is a phosphinic acid-containing ester prodrug that belongs to the angiotensin-converting enzyme (ACE) inhibitor, used for the treatment of heart failure and kidney failure due to high blood pressure and diabetes [1-2]. The molecular formula is $\mathrm{C}_{30} \mathrm{H}_{45} \mathrm{NNaO}_{7} \mathrm{P}$ and the molecular weight is 585.64. In the synthesis of fosinopril sodium, N-Hydroxybenzotriazole (HOBt), 1,3Dicyclohexylcarbodiimide and Cinchonidine were used as reagents. The residue of 1,3Dicyclohexylcarbodiimide reagent, if present, would exist as its byproduct 1,3-Dicyclohexyl urea (DCU). DCU considered as toxic substance according to OSHA 29 CFR 1910.1200. To improve the yield of the product, HOBt is used as condensation additive. (-)-Stereoisomer of Cinchonine commonly used in asymmetric synthesis, having acute oral toxicity of category 4 according to regulation (EC) No. 1272/2008 [EU-GHS/CLP]. These residual organic impurities can come through the manufacturing process of the drug substance, the criteria for their acceptance are based on pharmaceutical studies or known safety data [3]. In view of this, monitoring of HOBt, Cinchonidine and DCU in fosinopril drug substance is essential for preserving the desired quality of active substance. In the available literature, many of the analytical procedures have been reported for the estimation of fosinopril [4-6]. For Cinchonidine variable analytical methods were reported [7-12]. Pharmacokinetic evaluation of a 1,3-dicyclohexylurea nanosuspension formulation to support early efficacy assessment [13]. Hence, no method is available for analysis of these residual impurities. For the sensitivity of detection, we have chosen an analytic liquid chromatographic technique UPLC, instead of HPLC as this technology takes full advantage of chromatographic principles to run separations using columns packed with smaller particles and / or higher flow rates for increased speed, with superior sensitivity and resolution.

Subsequently, RP-UPLC method was developed and optimized to determine the contents of HOBt, Cinchonidine and DCU in fosinopril sodium drug substance with better separation of these peaks and sufficiently low levels of detection. To the best of our knowledge no report has been published on the analysis of HOBt, Cinchonidine and DCU in fosinopril drug substance in literature.

\section{Materials and Methods}

\section{Experimental}

\section{Chemicals, Reagents, and Samples}

The standard, samples of fosinopril sodium drug substance and known related substances of fosinopril sodium, such as fosinopril related substance-A (USP/EP), fosinopril related substance-B (USP/EP), fosinopril related substance-C (USP/EP), fosinopril related substance-D (USP/EP), fosinopril related substance-E (USP/EP) and fosinopril impurity-I\&J (EP) were procured from APL Research Centre (A division of Aurobindo Pharma Ltd., Hyderabad). Analytical reagent (AR grade) N-Hydroxybenzotriazole (HOBt), Cinchonidine, 1,3-Dicyclohexyl urea (DCU), potassium dihydrogen orthophosphate, disodium hydrogen orthophosphate, hydrochloric acid, sodium hydroxide, hydrogen peroxide, ortho-phosphoric acid, HPLC grade methanol and acetonitrile were procured from E Merck India. Highly purified water obtained from Millipore purification system.

\section{Ultra performance Liquid Chromatography (UPLC)}

Chromatographic separations were performed on UPLC system with acquity binary solvent manager, sample manager and PDA detector with Empower pro data handling system [Waters Corporation, MILFORD, MA 017 57, USA] was used. The mobile phase-A consists 
of potassium dihydrogen orthophosphate $(0.01 \mathrm{M}, \mathrm{pH}: 3.0 \pm 0.05$ with ortho-phosphoric acid) and mobile phase-B was acetonitrile. The analysis was carried out on Acquity UPLC HSS $\mathrm{C}_{18}$ (Waters Corporation Ltd.,) $100 \mathrm{~mm}$ long, $2.1 \mathrm{~mm}$ i.d., $1.8 \mu \mathrm{m}$ particle diameter column, thermo stated at $30^{\circ} \mathrm{C}$. Mobile phase was flushed through the column at a flow rate of $0.10 \mathrm{~mL} \mathrm{~min}-1$ and pump was in gradient mode and the program was as follows: Time $(\min ) / \mathrm{A}(\mathrm{v} / \mathrm{v}): \mathrm{B}(\mathrm{v} / \mathrm{v}) ; \mathrm{T}_{0.01} / 80: 20, \mathrm{~T}_{12} / 20: 80, \mathrm{~T}_{20} / 20: 80, \quad \mathrm{~T}_{20.2} / 80: 20, \mathrm{~T}_{25} /$ 80:20. The injection volume was used $8 \mu \mathrm{L}$. The acquisition time for the standard and sample was $20 \mathrm{~min}$. The analytes were monitored at $205 \mathrm{~nm}$. The mixture of water and methanol in the ratio of 70:30 v/v was used as diluent. The retention times of the HOBt, Cinchonidine and DCU peaks are at about 3.5, 4.0 and 10.5 minutes respectively. The resolution between HOBt and Cinchonidine peaks was not less than 1.5. Relative standard deviation for the peak areas of six replicate injections, of each standard peak is not more than $5.0 \%$.

\section{Standard and Sample Solutions}

\section{Preparation of Standard Solution}

Accurately weigh and transfer about $25 \mathrm{mg}$ each of 1-Hydroxybenzotriazole (HOBt), Cinchonidine and 1,3-Dicyclohexyl urea (DCU) reference standards into a $50 \mathrm{~mL}$ clean, dry volumetric flask, add $30 \mathrm{~mL}$ of methanol and sonicate to dissolve. Make up to volume with methanol. Dilute $3 \mathrm{~mL}$ of this solution to $100 \mathrm{~mL}$ with diluent. Further, dilute $3 \mathrm{~mL}$ of this solution to $100 \mathrm{~mL}$ with diluent. Filter through $0.22 \mu$ porous membrane.

\section{Sample Solution}

Accurately weigh and transfer about $60 \mathrm{mg}$ of sample into a $10 \mathrm{~mL}$ clean, dry volumetric flask, add $7 \mathrm{~mL}$ of diluent and sonicate to dissolve. Make up to volume with diluent. Filter through $0.22 \mu$ porous membrane.

\section{Results and Discussion}

\section{Method Development and Optimization}

The objective of this work is, to determine low level concentrations of $\mathrm{N}$ Hydroxybenzotriazole (HOBt), Cinchonidine and 1,3-Dicyclohexyl urea (DCU) in fosinopril sodium drug substance by a single method with reverse phase by using ultra performance liquid chromatography (UPLC) system. Method development was initiated with HOBt, Cinchonidine, DCU and drug solubility studies, based on the experiments mixture of water and methanol in the ratio of 70:30 v/v was chosen as diluent. Preliminary experiment was carried out by using $0.1 \% \mathrm{v} / \mathrm{v}$ ortho-phosphoric acid, as mobile phase-A and acetonitrile as mobile phase-B, gradient programme was run on Acquity HSS $\mathrm{C}_{18}, 1.8 \mu \mathrm{m} \quad(100 \mathrm{~mm} \mathrm{x}$ $2.1 \mathrm{~mm}$ ) column. In this trial these analytes were separated from each other, but DCU interfering with fosinopril related substance-A and poor resolution between HOBt and Cinchonidine was observed. After that many trials were performed to resolve this problem, using different stationary phases like BEH Phenyl, $\mathrm{C}_{8}$ and $\mathrm{C}_{18}$ with different phosphate buffers and mixed phosphate buffers at various $\mathrm{pH}(2.0$ - 7.0) by varying different gradient programme. In the trial, with $0.01 \mathrm{M}$ phosphate buffer at $\mathrm{pH} 3.0$, using Acquity UPLC HSS $\mathrm{C}_{18}, 1.8 \mu \mathrm{m}(100 \mathrm{~mm} \times 2.1 \mathrm{~mm})$ column, HOBt, Cinchonidine and DCU peaks were separated from each other with good resolution between HOBt and Cinchonidine peaks. Further any of related substance of fosinopril were not interfering with analyte peaks. While, with mixed phosphate buffers tailing of analyte peaks was observed. For better peak shapes and satisfactory resolution, again several trials were performed by varying $\mathrm{pH}$ of the phosphate buffer and column oven temperature. At $\mathrm{pH}$ 2.80, HOBt and Cinchonidine were merged, while at $\mathrm{pH} 3.20$, resolution between HOBt and Cinchonidine has been increased, 
but there is no change in retention time for DCU. At $25^{\circ} \mathrm{C}$ the resolution between $\mathrm{HOBt}$ and Cinchonidine was decreased, where as at $35^{\circ} \mathrm{C}$ resolution between these two peaks was increased.

Finally, satisfactory resolution with better peak shapes within a reasonable retention time at ambient temperature, was achieved on chromatographic conditions which have been mentioned in ultra performance liquid chromatography (UPLC), was used for validation study to evaluate its performance characteristics.

\section{Method Validation}

In order to determine the contents of HOBt, Cinchonidine and DCU in fosinopril sodium drug substance, the method was validated as per the ICH guidelines [14], individually in terms of specificity, forced degradation studies (stability indicating nature), limit of detection, limit of quantification, linearity, accuracy, precision (system precision, method precision and intermediate precision or ruggedness) and stability of sample solution.

\section{Specificity}

Specificity is the ability of the method to determine the individual analyte in presence of other related substances of drug substance. For specificity determination, diluent, all the related substances of fosinopril including $\mathrm{HOBt}$, Cinchonidine and DCU solutions were prepared individually and injected into UPLC as per methodology to confirm the retention times. After that solutions of fosinopril sodium drug substance, fosinopril sodium drug substance spiked with HOBt, Cinchonidine and DCU (spiked sample), fosinopril sodium drug substance spiked with all related substances of fosinopril including $\mathrm{HOBt}$, Cinchonidine and DCU (all spiked sample) were prepared and injected into UPLC as per methodology to confirm any co-elution with analyte peaks from respective diluent, any of related substances peaks and the peak homogeneity was verified for each analyte using waters empower software and found to be pure (purity angle should be less than purity threshold). An overlay chromatogram of diluent, fosinopril sodium drug substance, spiked sample with all spiked sample chromatogram is shown in Fig. 1. The stability indicating nature of the method was further evaluated by performing the forced degradation studies. As per International Conference on Harmonization (ICH), stress testing is to be carried out to identify the likely degradation products or to elucidate the inherent stability characteristics of the active substance [15]. Susceptibility to oxidation is one of the required tests and also hydrolytic, photolytic, thermal and humidity stress stability was required. It was observed that there was no interference observed for HOBt, Cinchonidine, DCU peaks and experiment results are shown in Table 1.

\section{$L O D$ and $L O Q$}

The limit of detection (LOD) and limit of quantification (LOQ), of HOBt, Cinchonidine and DCU were determined based on the residual standard deviation of a regression line and slope was adopted. Standard solution was injected into UPLC from lower concentration to higher concentration. A plot of peak area $\left(\mu \mathrm{V}^{*} \mathrm{sec}\right)$ versus concentration (ppm) was drawn and LOD/LOQ values were predicted by residual standard on deviation response (SD) and slope (S) method using the formula $3.3 \times \mathrm{SD} / \mathrm{S}$ for $\mathrm{LOD}$ and $10 \times \mathrm{SD} / \mathrm{S}$ for LOQ. For LOD and LOQ evaluation, solutions of HOBt, Cinchonidine and DCU were prepared at predicted concentration levels and precised by analyzing six times. An overlay chromatogram of LOD with LOQ solution chromatogram is shown Fig. 2. The achieved precised values were shown in Table 2. 
Table 1. Evaluation of forced degradation studies.

\begin{tabular}{|c|c|c|c|c|}
\hline $\begin{array}{l}\text { Type of } \\
\text { Degradation }\end{array}$ & Degradation Condition & $\begin{array}{c}\text { Degradation } \\
\text { of } \mathrm{HOBt} \\
(\% \mathrm{w} / \mathrm{w})\end{array}$ & $\begin{array}{c}\text { Degradation of } \\
\text { Cinchonidine } \\
(\% \mathrm{w} / \mathrm{w})\end{array}$ & $\begin{array}{l}\text { Degradation of } \\
\text { DCU }(\% \mathrm{w} / \mathrm{w})\end{array}$ \\
\hline Sample & - & Not detected & Not detected & Not detected \\
\hline \multirow{3}{*}{$\begin{array}{l}\text { Acid } \\
\text { degradation }\end{array}$} & $1 \mathrm{M} \mathrm{HCl} /$ Initial & - & - & - \\
\hline & $1 \mathrm{M} \mathrm{HCl} / 85^{\circ} \mathrm{C} / 60 \mathrm{~min}$ & - & - & - \\
\hline & $1 \mathrm{M} \mathrm{HCl} / 85^{\circ} \mathrm{C} / 120 \mathrm{~min}$ & - & - & - \\
\hline \multirow{3}{*}{$\begin{array}{l}\text { Alkaline } \\
\text { degradation }^{\mathrm{a}}\end{array}$} & $1 \mathrm{M} \mathrm{NaOH} /$ Initial & - & - & - \\
\hline & $1 \mathrm{M} \mathrm{NaOH} / 85^{\circ} \mathrm{C} / 60 \mathrm{~min}$ & - & - & - \\
\hline & $1 \mathrm{M} \mathrm{NaOH} / 85^{\circ} \mathrm{C} / 120 \mathrm{~min}$ & - & - & - \\
\hline \multirow{3}{*}{$\begin{array}{l}\text { Peroxide } \\
\text { degradation }^{\mathrm{a}}\end{array}$} & $30 \% \mathrm{H}_{2} \mathrm{O}_{2} /$ Initial & - & - & - \\
\hline & $30 \% \mathrm{H}_{2} \mathrm{O}_{2} / 85^{\circ} \mathrm{C} / 60 \mathrm{~min}$ & - & - & - \\
\hline & $30 \% \mathrm{H}_{2} \mathrm{O}_{2} / 85^{\circ} \mathrm{C} / 120 \mathrm{~min}$ & - & - & - \\
\hline $\begin{array}{l}\text { Thermal } \\
\text { degradation }\end{array}$ & $105^{\circ} \mathrm{C} / 120 \mathrm{Hrs}$ & Not detected & Not detected & Not detected \\
\hline $\begin{array}{l}\text { Humidity } \\
\text { degradation }\end{array}$ & $90 \% \mathrm{RH} / 25^{\circ} \mathrm{C} / 120 \mathrm{Hrs}$ & Not detected & Not detected & Not detected \\
\hline \multirow{2}{*}{$\begin{array}{l}\text { Photolytic } \\
\text { degradation }\end{array}$} & $10 \mathrm{~K} \mathrm{Lux} \mathrm{/} 120 \mathrm{Hrs}$ & Not detected & Not detected & Not detected \\
\hline & $2 \mathrm{~W} / \mathrm{M}^{2} / 120 \mathrm{Hrs}$ & Not detected & Not detected & Not detected \\
\hline
\end{tabular}

Table 2. Statistical data of linearity, LOD/LOQ for HOBt, Cinchonidine and DCU.

\begin{tabular}{|c|c|c|c|}
\hline Statistical parameters & HOBt & Cinchonidine & DCU \\
\hline Correlation coefficient & 0.9999 & 0.9999 & 0.9997 \\
\hline Intercept & -160 & -282 & -87 \\
\hline Residual standard on deviation response & 1375 & 1262 & 361 \\
\hline Slope & 5336 & 2675 & 340 \\
\hline Concentration range ( $\mathrm{ppm}$ ) & $0.4-112.9$ & $0.4-111.2$ & $3.7-113.2$ \\
\hline Limit of detection $(\mathrm{ppm})^{\mathrm{a}}$ & 0.85 & 1.56 & 3.52 \\
\hline Limit of quantification $(\mathrm{ppm})^{\mathrm{a}}$ & 2.57 & 4.72 & 10.67 \\
\hline Precision for Limit Of Detection (\% RSD) & 10.8 & 10.9 & 13.9 \\
\hline $\begin{array}{l}\text { Precision for Limit Of Quantification (\% } \\
\text { RSD) }\end{array}$ & 1.0 & 0.9 & 3.6 \\
\hline
\end{tabular}

${ }^{\mathrm{a}}$ Precised LOD and LOQ values. 

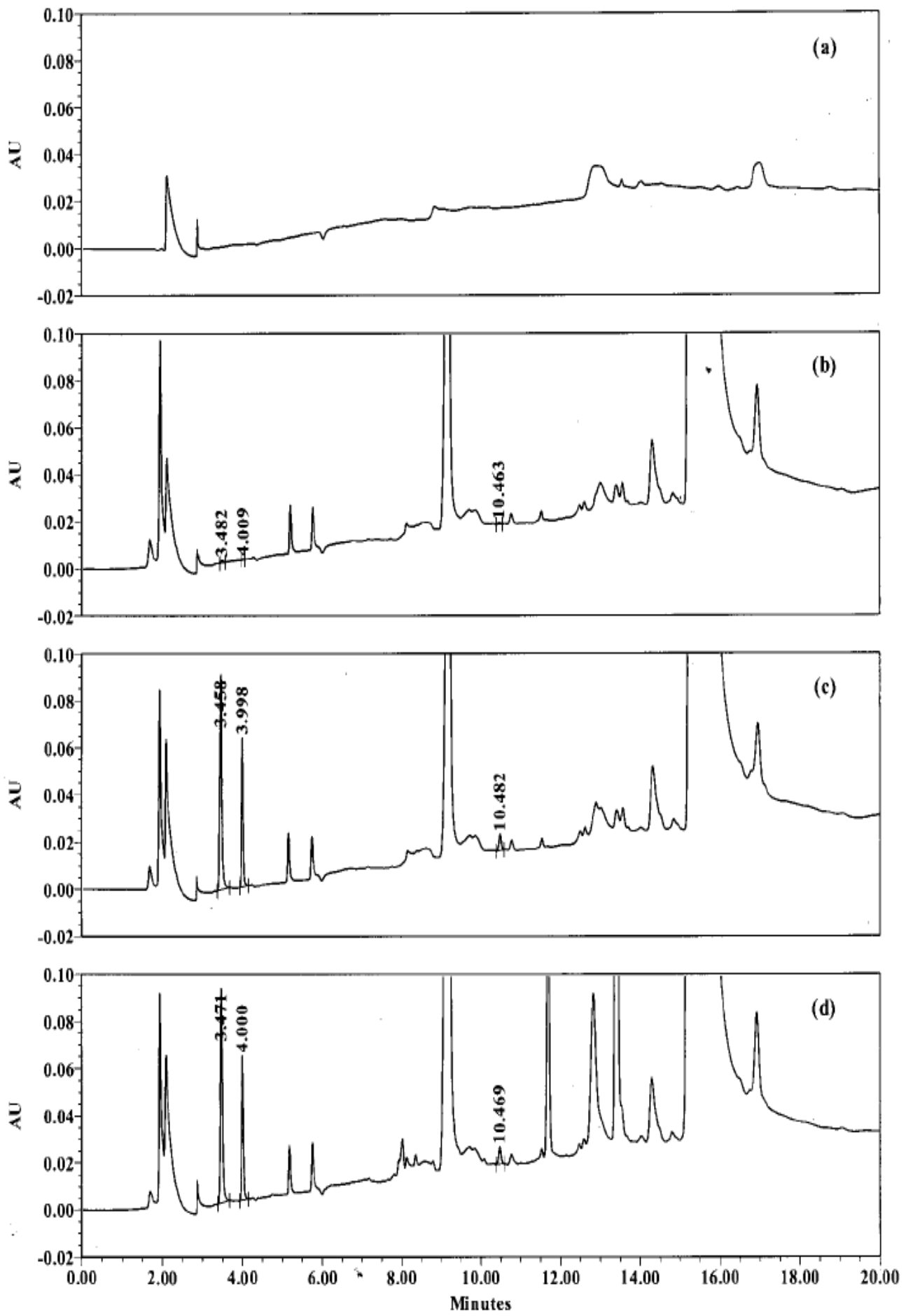

Fig. 1. A typical representative overlay chromatograms of (a) Diluent, (b) Fosinopril sodium drug substance, (c) Spiked sample and (d) All spiked sample 

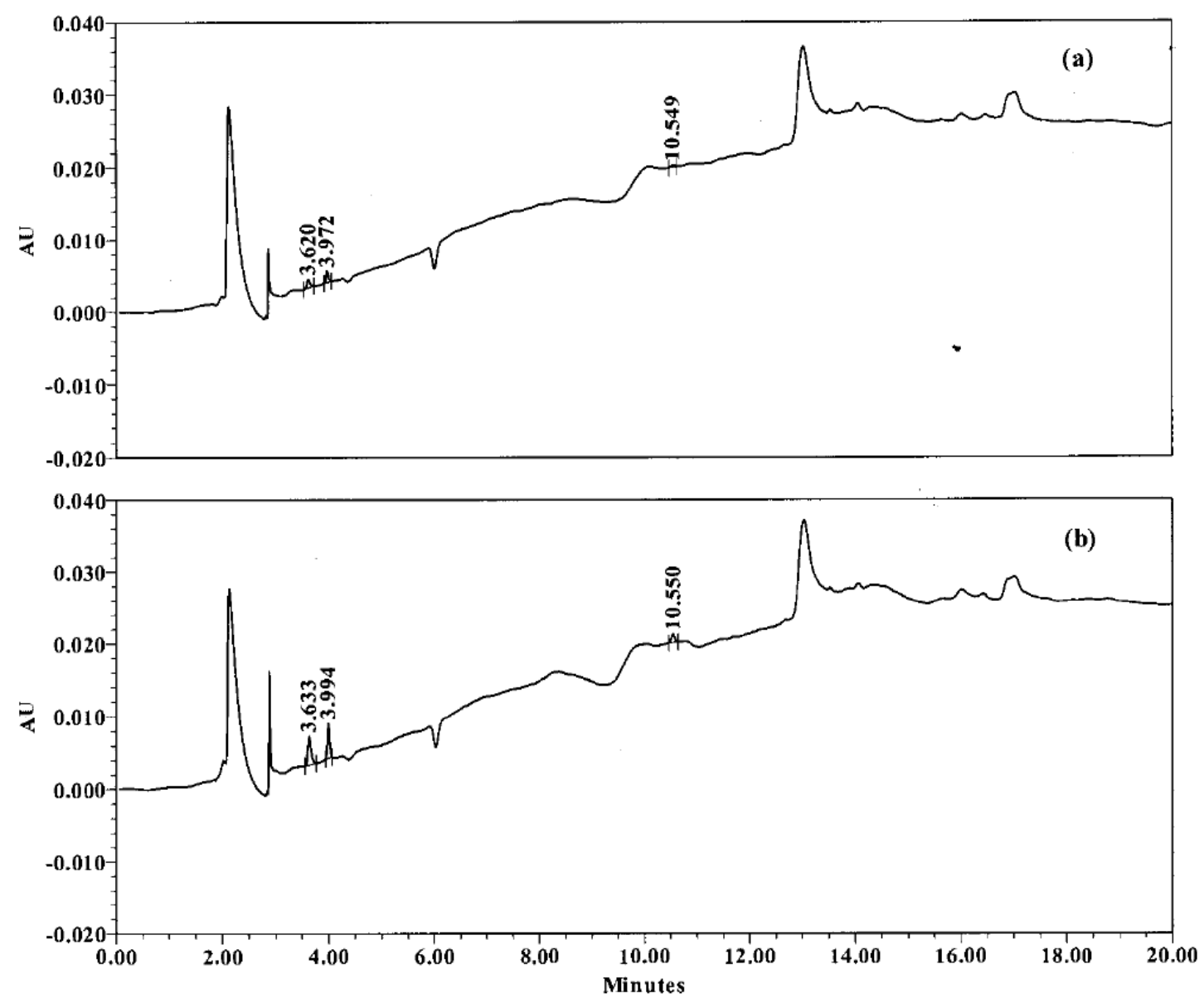

Fig. 2. A typical representative overlay chromatograms of (a) LOD solution, (b) LOQ solution

\section{Linearity}

The linearity of the method was determined by taking the same data obtained in LOD and LOQ. The data was subjected to statistical analysis using a linear-regression model. The statistical parameters slope, intercept, residual standard on deviation response and correlation coefficient values are calculated and shown in Table 2.

\section{Accuracy}

Accuracy of the method was performed by recovery experiments using standard addition technique. The recoveries were determined by spiking HOBt, Cinchonidine and DCU at four different levels (LOQ level, 35ppm, $75 \mathrm{ppm}$ and $115 \mathrm{ppm}$ ) into fosinopril sodium drug substance. These samples were prepared as per the test procedure, analyzed in triplicate and the percentage recoveries were calculated. The $\%$ recovery values for $\mathrm{HOBt}$, Cinchonidine and DCU ranged from $94.9-100.3,99.1-105.0$ and $98.0-102.0$ and the average \% recovery of four levels (twelve determinations) were 98.1, 102.6 and 100.3, respectively. The completely validated accuracy results are shown in Table 3. 


\section{Precision}

The precision was the study of the method using repeatability and reproducibility (ruggedness). The performance of the method was evaluated with replicate injections of standard and sample solutions. Standard solution was analyzed six times for checking the performance of the UPLC system under the chromatographic conditions on the day tested (system precision). The relative standard deviation for HOBt, Cinchonidine and DCU are $0.2,0.5$ and $0.9 \%$ respectively. The repeatability and reproducibility of the method was studied by analyzing six sample solutions separately. Repeatability was the intra-day variation (method precision), demonstrated by preparing six sample solutions individually using a single batch of fosinopril sodium drug substance spiked with HOBt, Cinchonidine and DCU at a known concentration level (about $75 \mathrm{ppm}$ ) as per test procedure and contents were determined. The relative standard deviation for the contents of $\mathrm{HOBt}$, Cinchonidine and DCU are $0.6,1.0$ and $1.4 \%$ respectively. The intermediate precision was the inter-day variation (ruggedness), was defined as the degree of reproducibility obtained by following the same procedure as mentioned for method precision experiment. The analysis of the same sample (which is used in the method precision) under a variety of conditions using different series of column, with different analyst on different day by preparing new standards and new mobile phase and the contents were determined. The relative standard deviation for the contents of HOBt, Cinchonidine and DCU are $0.6,0.8$ and $2.1 \%$ respectively. The completely validated precision (system precision, method precision and ruggedness) results are shown in Table 4.

Table 3. Accuracy data of HOBt, Cinchonidine and DCU.

\begin{tabular}{|c|c|c|c|c|c|c|c|c|c|c|c|c|}
\hline \multirow{2}{*}{ 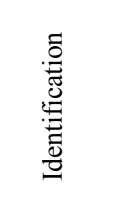 } & \multicolumn{4}{|c|}{$\mathrm{HOBt}$} & \multicolumn{4}{|c|}{ Cinchonidine } & \multicolumn{4}{|c|}{ DCU } \\
\hline & $\begin{array}{l}\text { LOQ } \\
\text { Level } \\
(\mathrm{ppm})\end{array}$ & $\begin{array}{c}35 \\
\text { ppm } \\
\text { Level }\end{array}$ & $\begin{array}{c}75 \\
\text { ppm } \\
\text { Level }\end{array}$ & $\begin{array}{c}115 \\
\text { ppm } \\
\text { Level }\end{array}$ & $\begin{array}{l}\text { LOQ } \\
\text { Level } \\
(\mathrm{ppm})\end{array}$ & $\begin{array}{c}35 \\
\text { ppm } \\
\text { Level }\end{array}$ & $\begin{array}{c}75 \\
\text { ppm } \\
\text { Level }\end{array}$ & $\begin{array}{c}115 \\
\text { ppm } \\
\text { Level }\end{array}$ & $\begin{array}{l}\text { LOQ } \\
\text { Level } \\
\text { (ppm) }\end{array}$ & $\begin{array}{c}35 \\
\text { ppm } \\
\text { Level }\end{array}$ & $\begin{array}{c}75 \\
\text { ppm } \\
\text { Level }\end{array}$ & $\begin{array}{c}115 \\
\text { ppm } \\
\text { Level }\end{array}$ \\
\hline $\begin{array}{l}\text { *Added } \\
\text { (ppm) }\end{array}$ & 2.56 & 36.75 & 73.43 & 109.67 & 4.70 & 37.83 & 75.60 & 112.91 & 10.63 & 37.79 & 75.51 & 112.79 \\
\hline $\begin{array}{l}\text { *Found } \\
\text { (ppm) }\end{array}$ & 2.43 & 36.85 & 72.22 & 108.46 & 4.66 & 39.25 & 77.53 & 118.57 & 10.42 & 37.69 & 76.99 & 114.40 \\
\hline $\begin{array}{l}\text { Recovery } \\
(\%)\end{array}$ & 94.9 & 100.3 & 98.4 & 98.9 & 99.1 & 103.8 & 102.6 & 105.0 & 98.0 & 99.7 & 102.0 & 101.4 \\
\hline *\% RSD & 0.2 & 0.9 & 0.1 & 0.7 & 0.5 & 3.4 & 0.2 & 0.5 & 0.8 & 0.7 & 0.9 & 1.3 \\
\hline
\end{tabular}

\section{Solution Stability}

The sample solution was prepared by the addition of HOBt, Cinchonidine and DCU at a known concentration level (about $75 \mathrm{ppm}$ ) into fosinopril sodium drug substance as per test procedure. The stability of sample solution was tested by recording the chromatograms freshly prepared and at different intervals with the gap of every one hour up to 12 hours by keeping, sample cooler temperature at $25^{\circ} \mathrm{C}$. The $\%$ difference in the peak areas of analytes, from freshly to different time interval was found to be less than 2.0. The results concluded that sample solution was stable for 12 hours at ambient temperature. 
Table 4. Statistical data of precision for HOBt, Cinchonidine and DCU.

\begin{tabular}{|c|c|c|c|}
\hline \multicolumn{4}{|c|}{ Repeatability (System precision) Area $\left(\mu \mathrm{V}^{*} \mathrm{sec}\right)$} \\
\hline & HOBt & Cinchonidine & DCU \\
\hline 1 & 402380 & 201564 & 26855 \\
\hline 2 & 400574 & 203038 & 26774 \\
\hline 3 & 400514 & 204398 & 26492 \\
\hline 4 & 401701 & 203620 & 27240 \\
\hline 5 & 402107 & 203401 & 27033 \\
\hline 6 & 401797 & 203873 & 26993 \\
\hline Avg & 401512 & 203316 & 26898 \\
\hline SD & 787 & 972 & 255 \\
\hline$\%$ RSD & 0.2 & 0.5 & 0.9 \\
\hline \multicolumn{4}{|c|}{ Reproducibility (Method precision) (ppm) } \\
\hline 1 & 70 & 73 & 78 \\
\hline 2 & 70 & 73 & 76 \\
\hline 3 & 70 & 74 & 75 \\
\hline 4 & 69 & 74 & 76 \\
\hline 5 & 70 & 75 & 77 \\
\hline 6 & 70 & 74 & 76 \\
\hline Avg & 70 & 74 & 76 \\
\hline SD & 0.41 & 0.75 & 1.03 \\
\hline \%RSD & 0.6 & 1.0 & 1.4 \\
\hline \multicolumn{4}{|c|}{ Reproducibility (Ruggedness) (ppm) } \\
\hline 1 & 72 & 78 & 77 \\
\hline 2 & 72 & 77 & 77 \\
\hline 3 & 72 & 77 & 77 \\
\hline 4 & 71 & 76 & 73 \\
\hline 5 & 72 & 77 & 76 \\
\hline 6 & 72 & 77 & 75 \\
\hline Avg & 72 & 77 & 76 \\
\hline SD & 0.41 & 0.63 & 1.60 \\
\hline \%RSD & 0.6 & 0.8 & 2.1 \\
\hline
\end{tabular}

\section{Conclusion}

A simple and sensitive reverse phase UPLC method has developed and validated for the simultaneous determination of N-Hydroxybenzotriazole (HOBt), Cinchonidine and 1,3Dicyclohexyl urea (DCU) contents in fosinopril sodium drug substance. The results of various validation parameters demonstrated that the method is specific, stability indicating, sensitive, linear, precise and accurate. Henceforth, the proposed method is simple and userfriendly, for the determination of HOBt, Cinchonidine and DCU contents in fosinopril sodium drug substance.

\section{Acknowledgements}

The authors gratefully acknowledge the management of APL Research Centre (A Division of Aurobindo Pharma Ltd., Hyderabad), for giving us the opportunity to carry out the present work. The authors are also thankful to the colleagues of Analytical Research Department and Department of Chemistry, Sri Krishnadevaraya University. 


\section{References}

1. Pilote L, Abrahamowicz M, Eisenberg M, Humphries K, Behlouli H, Tu JV, CMAJ., 2008, 178, 1303-11.

2. Chang NC, Shih CM, Bi WF, Lai ZY, Lin MS, Wang TC, Cardiovasc Drugs Ther., 2002, 16, 141-7.

3. ICH Harmonised Tripartite guideline, Impurities in new drug substances Q3A (R2). Step 42006.

4. Jiang Guoqiang, Chen Guiliang, Chinese journal of modern applied pharmacy., 199904 .

5. D. Ivanovic, M. Medenica, B. Jancic, A. Malenovic and S. Markovic, Chromatographia., 2004, 60, S87-S92.

6. B. Jancic, M. Medenica, D. Ivanovic, S. Jankovic and A. Malenovic, Journal of Chromatography A., 2008, 1189, 366-373.

7. A. Navas Diaz, F. Garcia Sanchez, A. Aguilar Gallardo and A. Garcia Pareja, Instrum. Sci. Technol., 1996, 24, 47-56.

8. Garcia Sanchez F, Navas Diaz A, Torijas MC, Nava Baro E, Algarra M, Anal Chim Acta., 2009, 639, 67-72.

9. P. B. Marshall and E. W. Rogers, Biochem J., 1945, 39, 258-260.

10. H. S. Grant, J. H. Jones, Anal. Chem., 1950, 22, 679-681.

11. Masao Horie, Mitsuo Oishi, Fusako Ishikawa, Tetsuya Shindo, Akiko Yasui, Shuzo Ogino, Koichi Ito, Journal of AOAC INTERNATIONAL., 2006, 89, 1042-1047.

12. Magda M. Ayad, S.E. Khayyal and N.M. Farrag, Spectrochimica Acta Part B: Atomic Spectroscopy., 1985, 40, 1205-1209.

13. Jan L. Wahlstrom, Po-Chang Chiang, Sarbani Ghosh, Chad J. Warren, Steve P. Wene, Lesley A. Albin, Mark E. Smith, Steven L. Roberds, Nanoscale Res Lett., 2007, 2, 291-296.

14. International Conference on Harmonization of technical requirements for registration of pharmaceuticals for human use, ICH harmonized tripartite guideline, Validation of analytical procedures: Text and methodology Q2(R1), step 42005.

15. International Conference on Harmonization of technical requirements for registration of pharmaceuticals for human use, ICH harmonized tripartite guideline, Stability testing of new drug substances and products Q1A(R2), step 42003. 


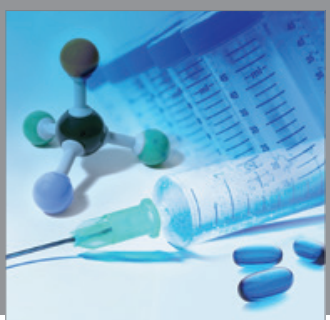

International Journal of

Medicinal Chemistry

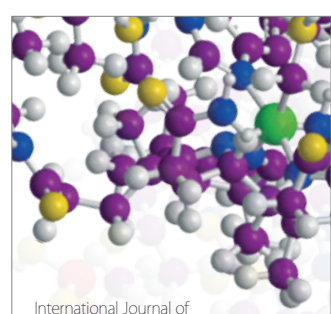

Carbohydrate Chemistry

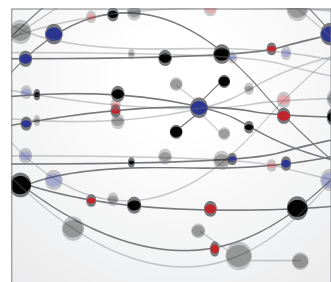

The Scientific World Journal
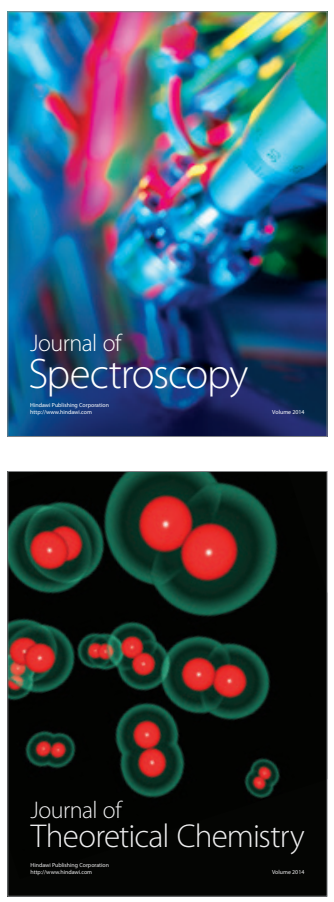
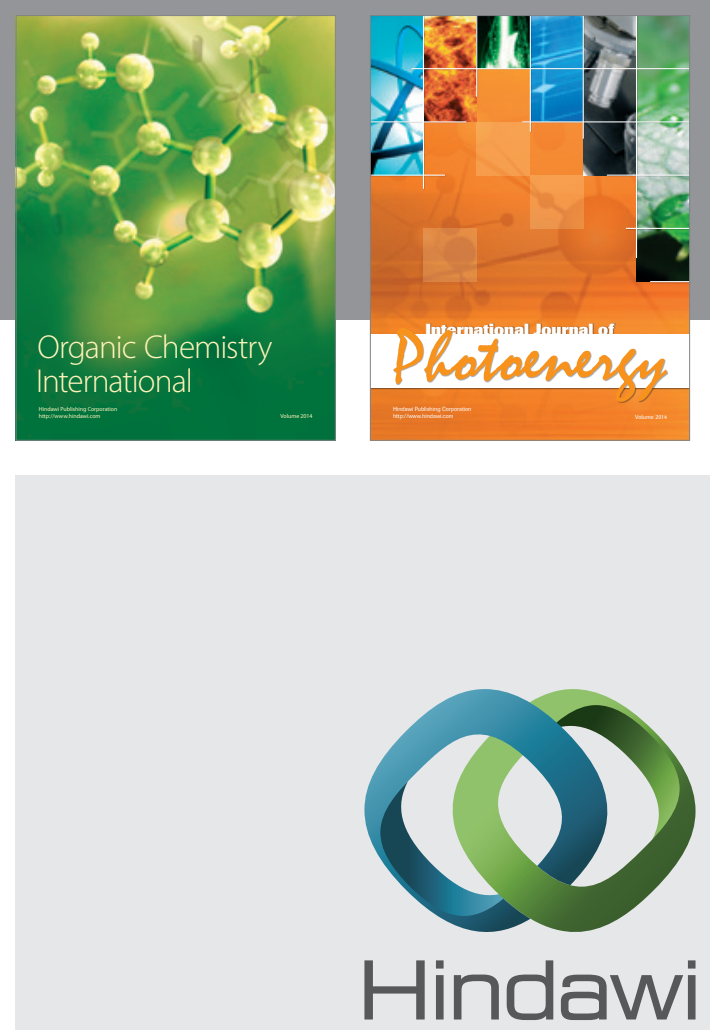

Submit your manuscripts at

http://www.hindawi.com
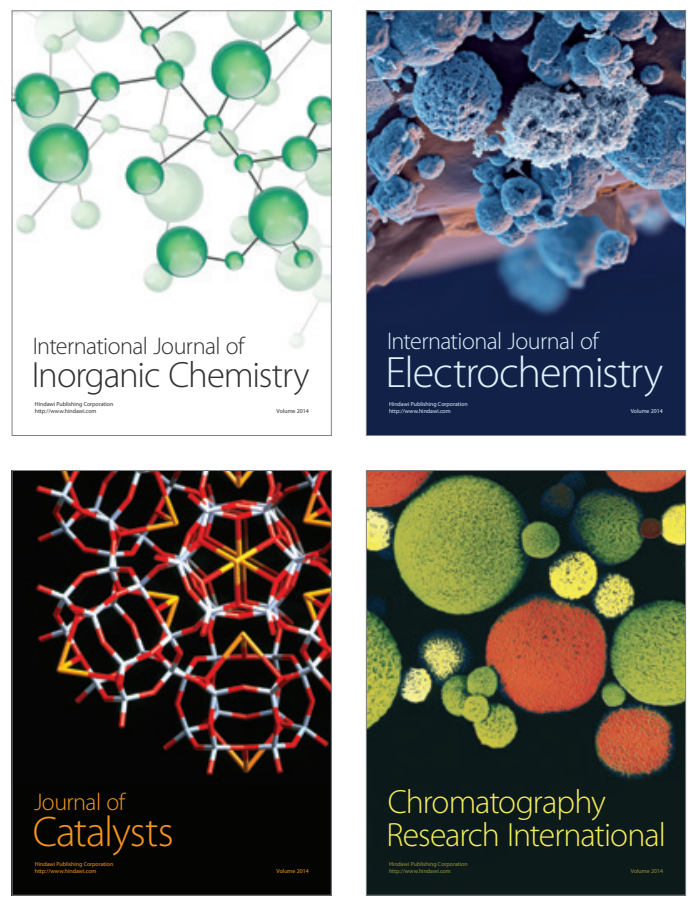
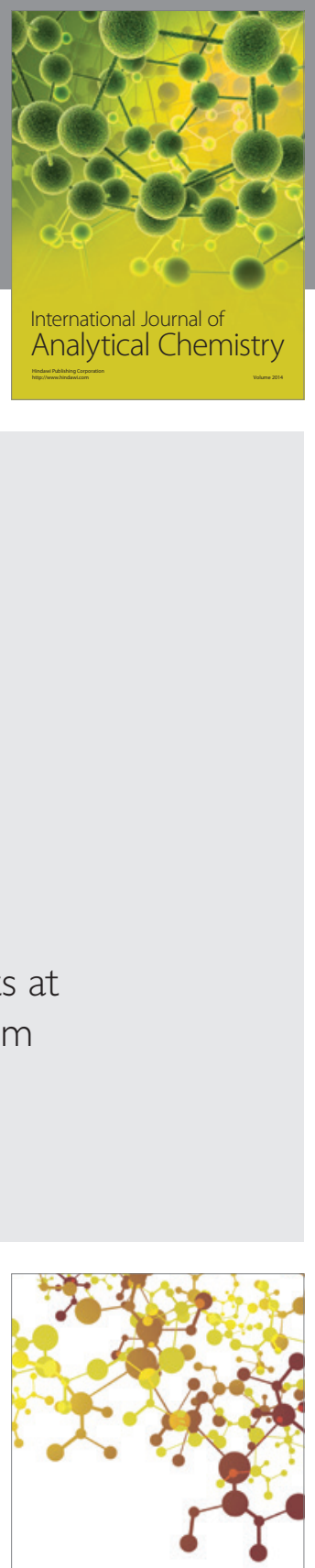

Journal of

Applied Chemistry
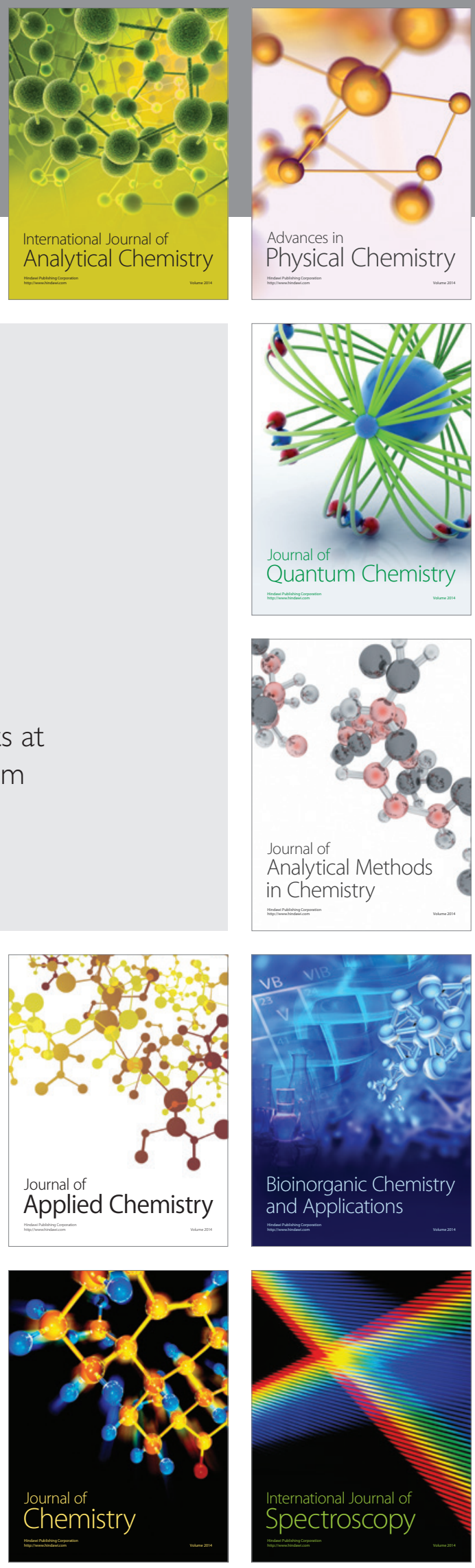